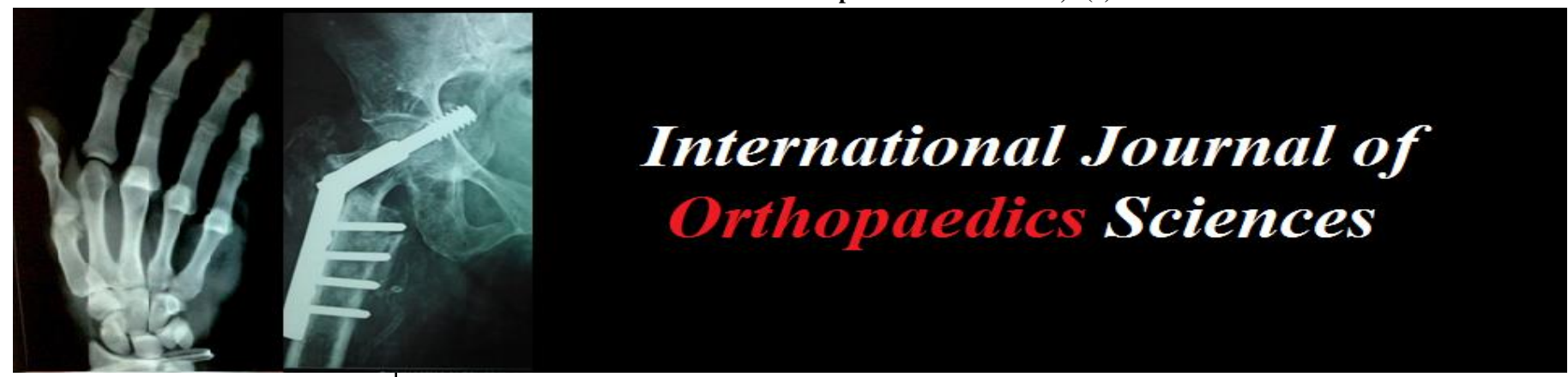

ISSN: $2395-1958$

IJOS 2018; 4(3): 616-622

(C) 2018 IJOS

www.orthopaper.com

Received: 28-05-2018

Accepted: 29-06-2018

Dr. Siddaram N Patil Prof \& HOD, ANH, NRIIMS, Sangivalasa, Visakhapatnam, Andhra Pradesh, India

Dr. G Parameshwar Rao Assistant Professor,

ANH, NRIIMS, Sangivalasa, Visakhapatnam,

Andhra Pradesh, India

\section{Prospective study of 30-cases of fracture distal third femur managed by retrograde distal femoral intramedullary nail}

\author{
Dr. Siddaram N Patil and Dr. G Parameshwar Rao
}

DOI: $\underline{\text { https://doi.org/10.22271/ortho.2018.v4.i3k.108 }}$

\section{Abstract}

Background and objectives: Fracture of distal third of femur is encountered because these fractures most often result from high velocity injuries as femur is the largest bone of the body. It is one of the principal load bearing bones in the lower extremity ${ }^{[1]}$. One must have a high index of suspicion for complications or other injuries as it can cause prolonged morbidity and extensive disability like joint stiffness due to post traumatic arthritis unless treatment is appropriate. Distal femur fractures make up to $6 \%$ of all femoral fractures. Most high energy distal femoral fractures occur in males 15-50 years and low energy fractures occur in osteoporotic women more than 50. Most commonly RTA 53\% and fall at home $33 \%{ }^{[7]}$. In rural India, workplace injury such as fall from height is also common. Currently surgery is indicated for femur fractures because of high rate of union, low rate of complication and advantage of early stabilization which decreases morbidity and mortality in patients. Regardless of the method of treatment, the following principles are agreed upon i.e. restoration of alignment, rotation and length, preservation of blood supply to aid union, prevent infection, rehabilitation of the extremity and there by the patient ${ }^{[4]}$.

A method closely approaching this perfection is retrograde intramedullary interlocking nailing which improves the torsional and axial stability and offers a more biological method of fixation with less devitalisation of soft tissues ${ }^{[4,8]}$. It has improved post-operative knee function with decreased operative time, blood loss, bone grafting, and non-union rates ${ }^{[8]}$. Result is early recovery, lesser hospital stay, early rehabilitation with good results and is economical ${ }^{[6]}$. Surgical stabilization of osteoporotic bones and pathological fractures has increased due to retrograde nails ${ }^{[6]}$.

The present study is to understand the functional outcome and to minimize operative mistakes and complications of surgical management of distal femur fractures with retrograde nailing.

Methods: 30 patients with supracondylar femur fracture were studied, in Anil Neerkonda Hospital, NRI institute of Medical Sciences. Visakhapatnam in between June 2016 to May 2018. RIS nail was inserted through intercondylar notch. These nails have advantage of being load shearing devices, requiring little soft tissue dissection, infrequently needing bone grafting and technically easier. Preserving fracture hematoma, decreased blood loss, less operative time and decreased infection.

Results: In 30 patients, male predominate $(93.3 \%)$ in this study. RTA was the chief cause of fracture. Surgery was performed within 1.9 days average, there were 5 open type and 25 closed type of fracture. radiological union was seen in 16-24 weeks. Average patient was followed up for 6 months. Average knee flexion was $115^{\circ} .1$ died, 1 screw breakage and 2 had pulmonary embolism. 3 shortening of limb, 3 stiffness and 7 delayed union. 15(51.7\%) excellent results, 6(20.6\%) good results, 7(24.\%) fair results and $1(3.4 \%)$ poor result.

Interpretation and Conclusion: Retrograde intramedullary nailing is a good fixation system for supracondylar femur fractures with less operative time and blood loss. By closed reduction, not disturbing fracture hematoma and even in open reduction less soft tissue dissection and thus reducing complications like infection, stiffness, distal screw related local symptom is a common problem and is related to implant and technique and has a definite learning curve. Utmost aseptic precaution great care required to prevent infection. Non-requirement of bone graft decreases the morbidity. Early surgery, closed reduction, at least two screws in each fragment and early post-operative knee mobilization are essential for good union and good knee range of motion.

Keywords: Distal third femur fracture, retrograde supracondylar nail, closed reduction

\section{Introduction}

This is an era of rapid industrialization and fast pace of life which has led to concomitant rise in road traffic accident (RTA), that cripple many lives as well as increased life expectancy, old
Correspondence

Assistant Professor,

ANH, NRIIMS, Sangivalasa,

Visakhapatnam,

Andhra Pradesh, India 
age population, carrying dangers of osteoporosis and fractures. So these major factors contribute to such complex fractures of distal femur. The incidence of distal femoral fractures is approximately $37 / 1,00,000$ person years ${ }^{[8]}$. Distal femur fractures make up to $6 \%$ of all femoral fractures. Most high energy distal femoral fractures occur in males 15-50 years and low energy fractures occur in osteoporotic women more than 50 years. Most common mode of injury is RTA $(53 \%)$ and fall at home $(33 \%)^{[7]}$. In rural India, workplace injury such as fall from height is also common. Supracondylar femoral fractures are often difficult to treat and they are notorious for many complications ${ }^{[10]}$. In the early 1960 s, there was a great reluctance towards operative management of this fracture because of high incidence of infection, non-union, mal-union, inadequate fixation and lack of proper instrumentation. The orthodox management of distal third femur was along the principle of Watson Jones ${ }^{[12]} \&$ John Charnley [13]. This comprised of skeletal traction [11], manipulation of fracture and external immobilization in the form of casts and braces. These methods however were associated with complications like deformity, shortening, fracture disease, knee stiffness, joint incongruity, mal-union, muscle wasting, knee instability and early arthritis [13, 14]. Dissatisfaction with the results of these orthodox treatments were commonly encountered, which lead to the development of newer techniques of fracture managements. It is now recognized that distal femoral fractures are best treated with open/closed reduction and surgical stabilization ${ }^{[15]}$. The osteosynthesis in the distal femur could be difficult because of thin cortex, comminution, osteopenia, complex injuries associated soft tissue injuries, a distal wide medullary canal and involvement of the knee joint. Most surgeons agree that distal femoral fractures need to be treated operatively to achieve optimal outcomes ${ }^{[9]}$. The current method of open reduction and internal fixation has become evident in the recent years with good results being obtained with the AO blade plate, dynamic condylar screw and other implant systems like intramedullary supracondylar nails and recently locking compression plate.

The options for surgical treatment are many but after thorough research the technique of retrograde nailing was the most ideal. This load sharing device gave good results with minimal soft tissue dissection and good stability. Supracondylar fractures tend to collapse into varus. During application of AO blade plate or dynamic condylar screw, the shaft of femur is often pulled laterally displacing the line of weight bearing, lateral to the anatomic axis of condyle. This creates rotational movements at the fracture site that causes pulling off the blade plate or condylar screws leading to fatigue fracture of the plates. Also, the presence of osteoporotic bone leads to fixation failures with screws and plates cutting of the soft bone. The obvious advantage of an intramedullary device is that it aligns the femoral shaft with condyles reducing the tendency to place varus movement at the fracture site. The reduced bending movement of an intramedullary device has substantially reduced failure of fixation in osteoporotic bone. Intramedullary nails offer potential biomechanical advantages over plates and screws because their intramedullary location results in less stress on the implant, they have the potential for load sharing, and can be inserted with minimal stripping of soft tissue. Given the appropriate fracture patterns, ante grade IM nailing in the treatment of distal femoral fractures has been associated with angular deformities because of inability of distal interlock of the ante grade nail to achieve control of the small and often osteoporotic distal fracture fragment ${ }^{[18]}$. A retrograde intramedullary supracondylar nail has got distinct advantages of preservation of fracture hematoma, reduced blood loss, minimal tissue damage, less operative time and reduced rate of infection. Controversy still remains regarding the optimum device for distal femur fixation. The type of device depends on variables, fracture personality and soft tissues. With this study we aim to evaluate the surgical outcome of supracondylar fracture of femur, treated by close/ open reduction and internal fixation using retrograde intramedullary supracondylar nail.

\section{Methodology}

30 patients with supracondylar femur fracture were studied. RIS nail was inserted through intercondylar notch and followed up from the time of admission to a minimum of 6 months of postoperatively. All the fractures in this series were post-traumatic.

Inclusion criteria was patients above 18 years, Fracture distal one third femur shaft $(15 \mathrm{cms})$ and extra articular supracondylar fractures. Exclusion criteria was distal femur fractures AO type B and C and Gustillo Anderson open type III C.

\section{Procedure}

Position the patient supine on a radiolucent table with the knee in $30^{\circ}$ flexion. The knee is supported by a cushion, or rolled sheets. The limb was scrubbed for 5 minutes with surgical betadine scrub followed by painting with povidone iodine and medicated spirit and draping with sterile drapes so that the knee joint and distal thigh were in the operative field. A midline incision of $4 \mathrm{~cm}$ was taken from inferior pole of patella up to tibial tuberosity. The paratenon over patellar tendon was sharply incised and patellar tendon was split in the midline along the direction of the fibers. Sleeve was then inserted into the joint through the split tendon and positioned against the inter-condylar notch. Its position was checked under image intensifier and the awl was inserted then removed and guide wire passed through the entry point. The sleeve was then removed and the fracture was reduced under image intensifier control and guide wire passed in proximal fragment. The distal fragment was then reamed with cannulated reamer provided with instrumentation set. The predetermined nail of adequate diameter and length was then loaded over the jig with the help of conical bolt keeping in mind the side to be operated so that jig was placed laterally and the convexity of nail facing anteriorly. The nail was then inserted over the guide wire through the entry point made previously through distal and then proximal fragment. Its position was confirmed on image intensifier and then depending on the length of the nail, the proximal holes were locked with the help of corresponding markings on the jig. After taking stab incision over the corresponding lateral skin, the soft tissues were separated by blunt dissection with the help of hemostat and drill sleeve and drill guide for $4.5 \mathrm{~mm}$ drill bit were inserted through the fenestrations provided over the jig, through the stab incision flush with the lateral cortex. The lateral and medial cortex were drilled with $4.5 \mathrm{~mm}$ drill bit. Continuity of drill holes in both the cortices with the locking hole of nails was confirmed with sounding (tik-tik) technique. The required length of locking bolt was measured with the help of depth gauge and interlocking bolt of $4.9 \mathrm{~mm}$ thread diameter passed from lateral to medial cortex engaging the locking hole in the nail. Either single or both holes were locked proximally. Similarly, the distal holes were locked in 
one, two or three numbers. The jig was then disengaged, the joint was washed thoroughly to remove the debris. Tourniquet was released, hemostasis achieved and incision closed in layers. Particular attention was paid to repair paratenon of patellar tendon.

\section{Postoperative}

Tight compression bandage was given to patients post operatively. If presence of any concomitant ispilateral injuries were present an above knee posterior slab was applied. In closed nailed patients, static quadriceps and active or active assisted bedside knee mobilization was started from second postoperative day. Follow up done 1, 3, and 6 months postoperatively. Patients were given training and made to walk with non-weight bearing ambulation with walker. As the patient gained confidence, toe touch walking was allowed by the $6^{\text {th }}$ week. Further, weight bearing was allowed depending on the clinical and radiological picture. The initial fracture geometry, intra articular commination, stability of fixation were the major factors considered while advising progressive weight bearing. At each follow-up patient was assessed as regards clinico-radiological union in the form of pain at fracture site, thickening at fracture site, warmth at fractures site, radiographic alignment, evidence of callus seen, knee range of motion, extensor lag and shortening. For each fracture type, the long-term results were evaluated using Neer's rating system which assigns points for pain, working and walking capacity, range of movement, radiological appearance, etc.

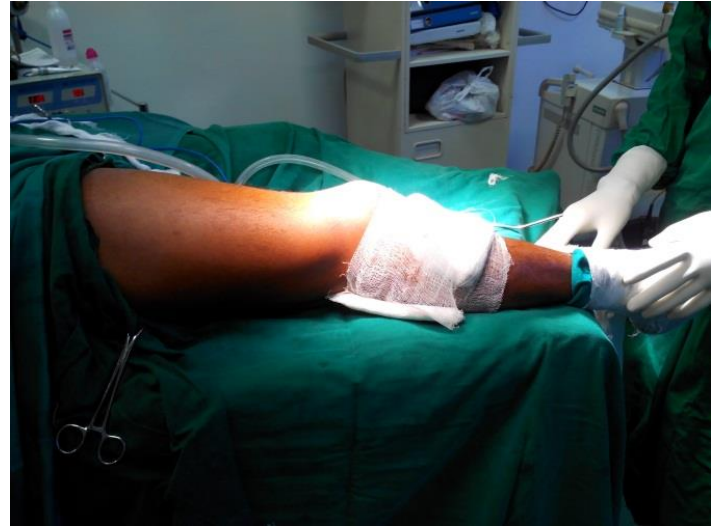

(a)

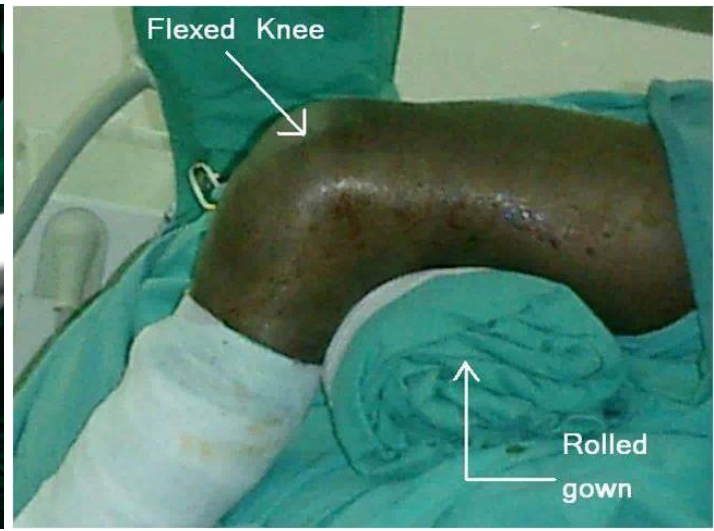

(b)

Position of patient

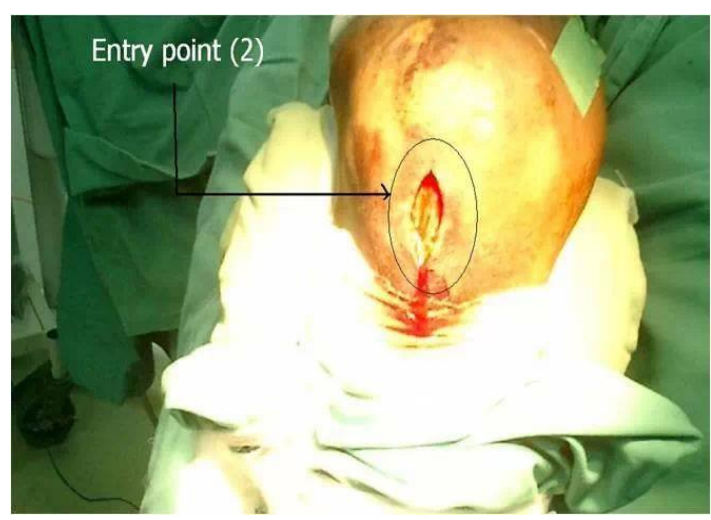

(c)

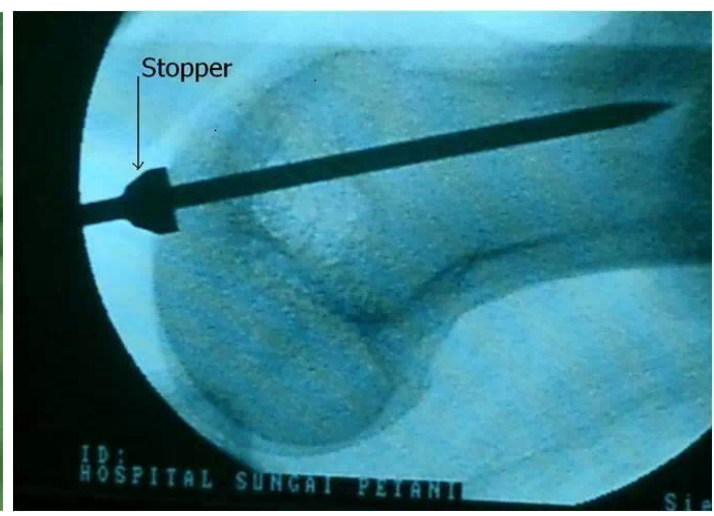

(d)

Incision and entry point as seen in C-arm

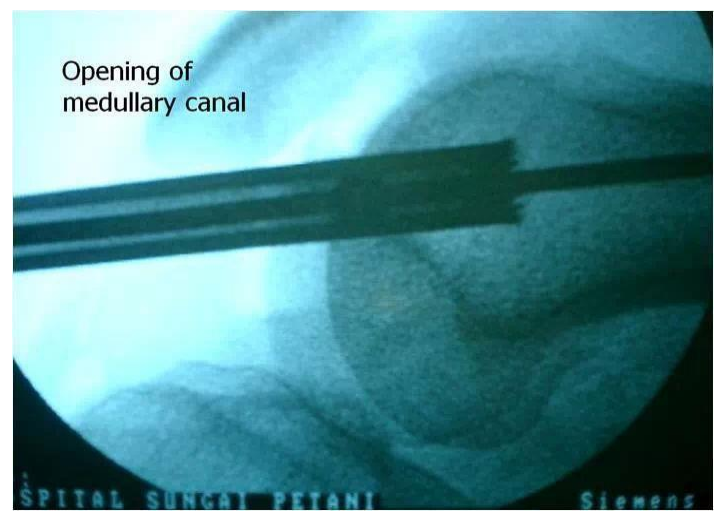

(e)

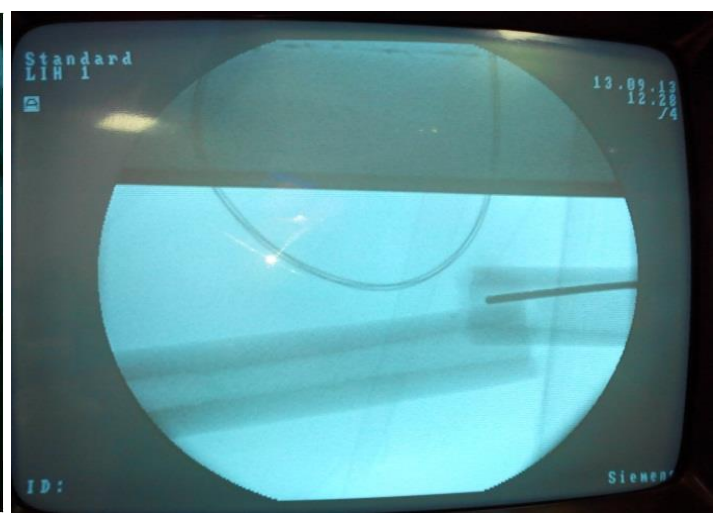

(f)

C-arm images images of guide wire insertion 


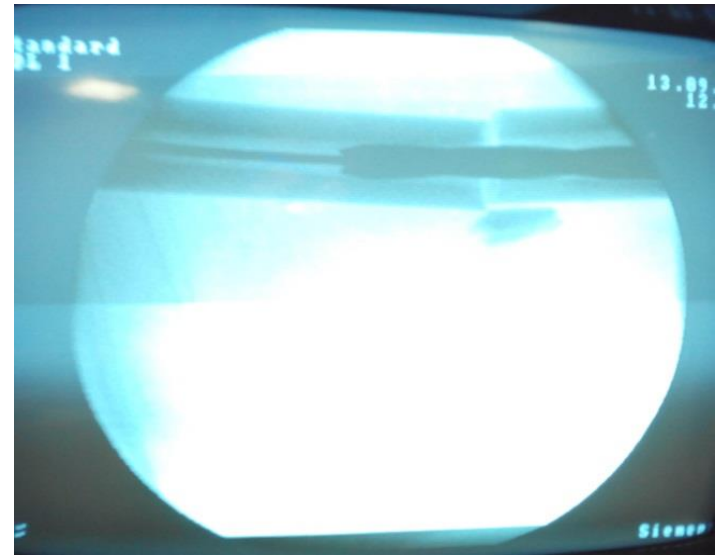

(g)

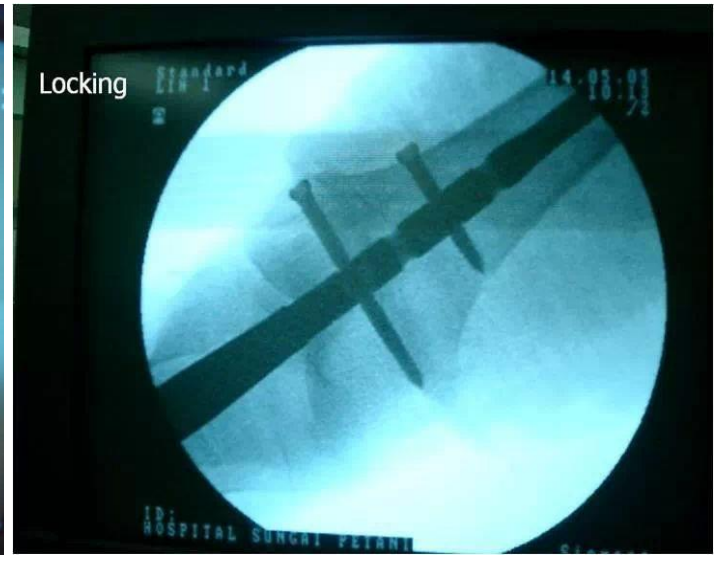

(h)

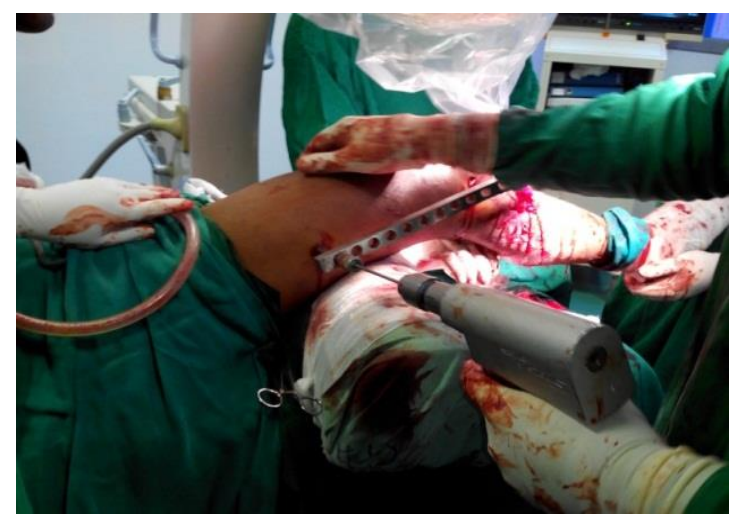

(i)

Image showing proximal locking for nail

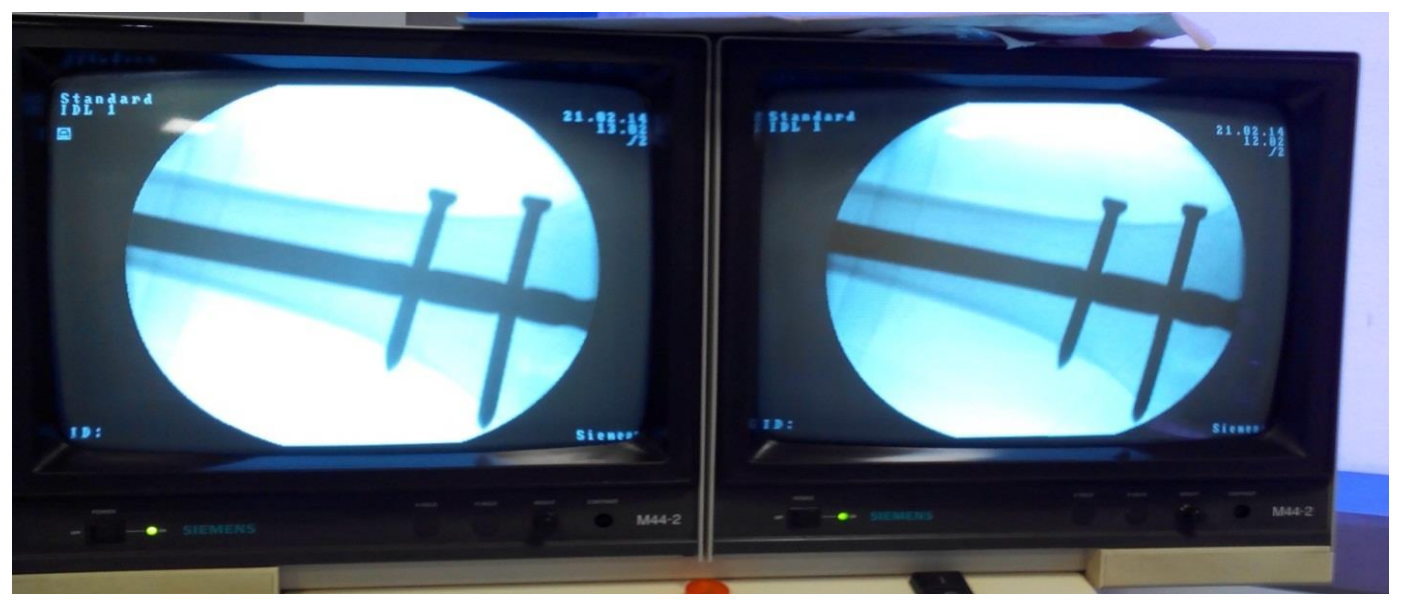

(j) C-arm images after locking

Fig 1: intra-operative picture

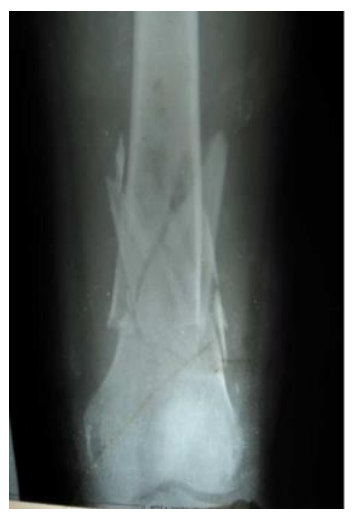

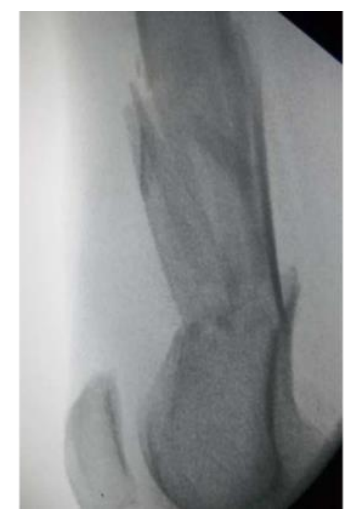

(a)
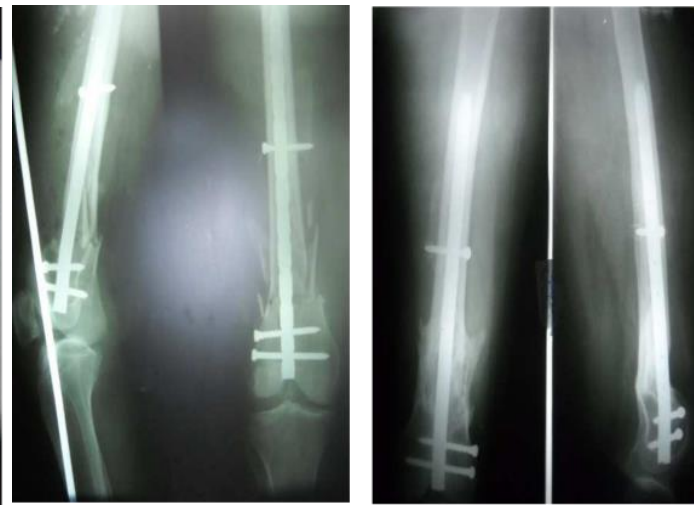

(b) 

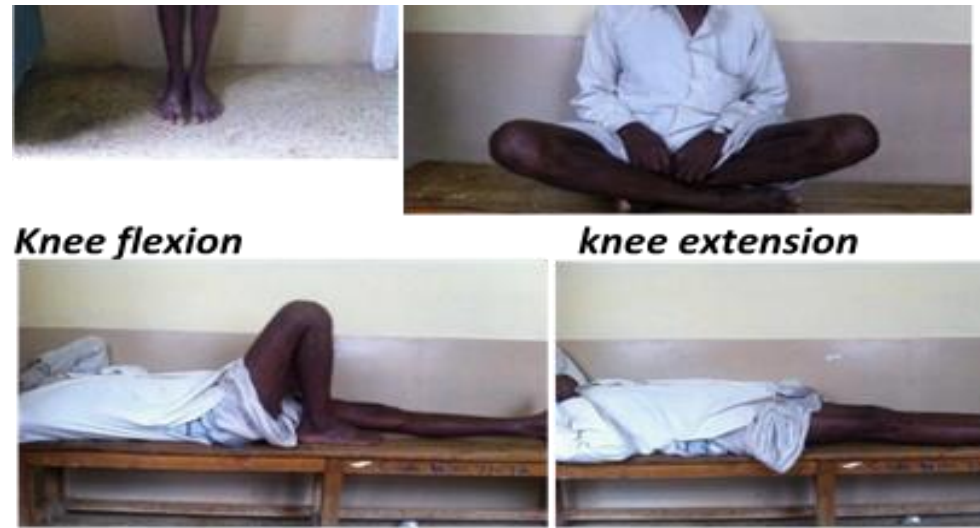

knee extension

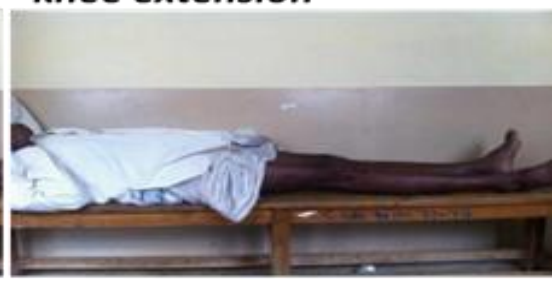

(c)

Fig 2: (a) x rays showings a AO type III fracture (b) fixed with supracondylar nail (c) post-operative ROM
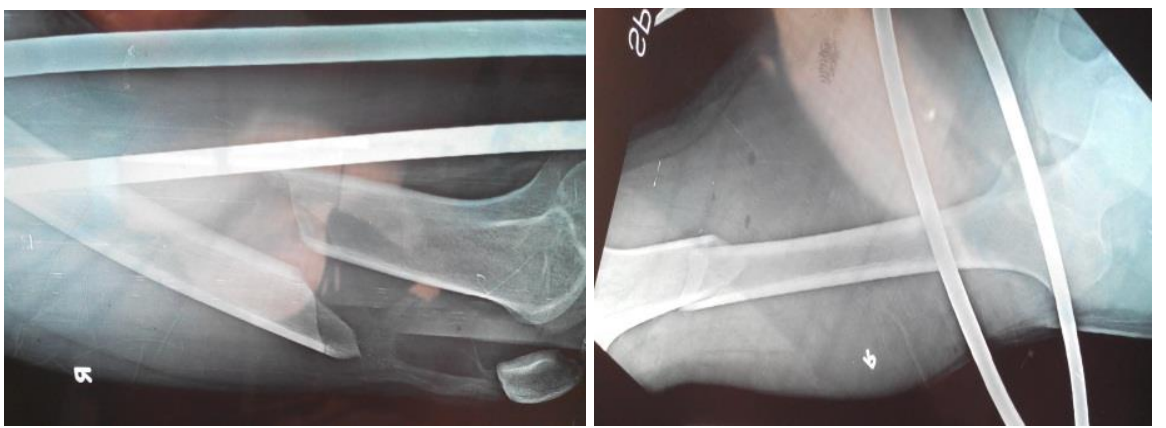

(a)
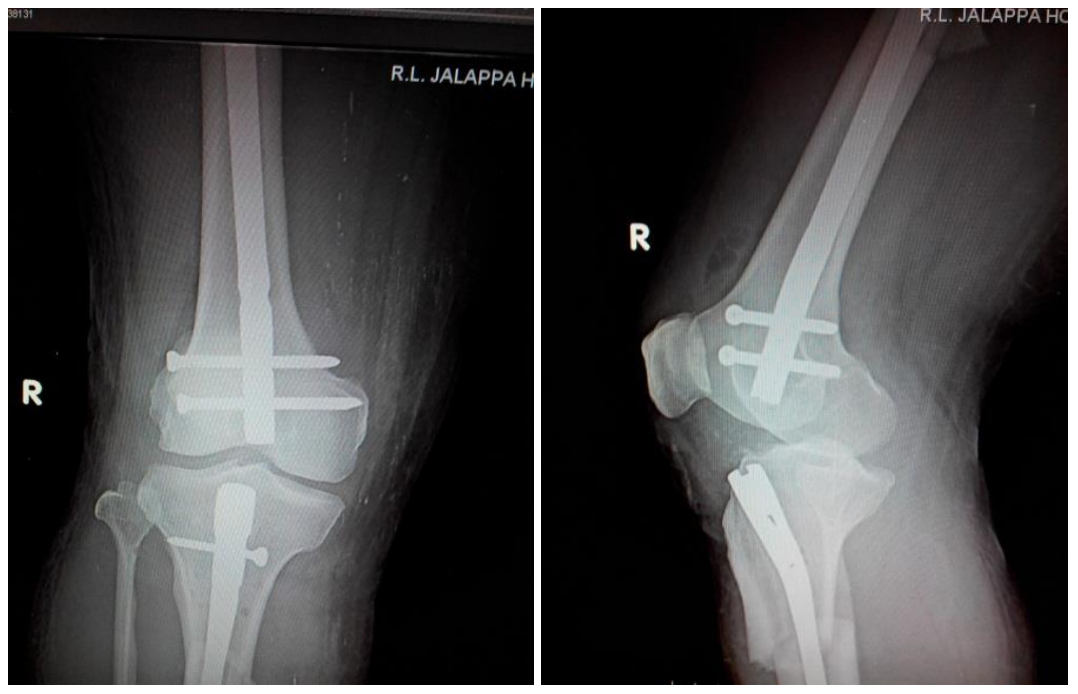

(b)

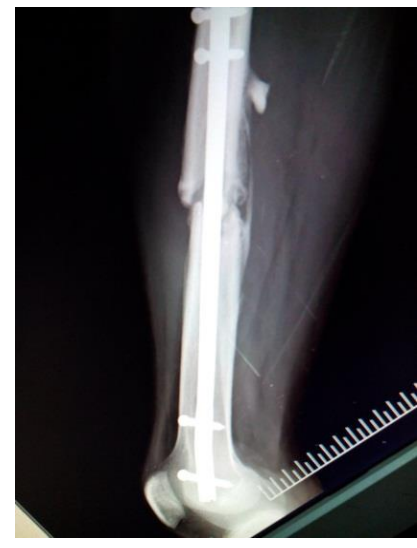

(c)

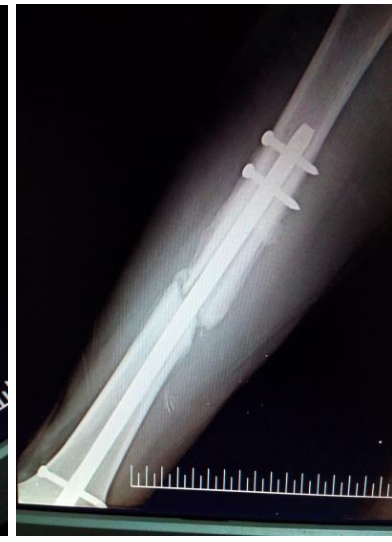

山上 .

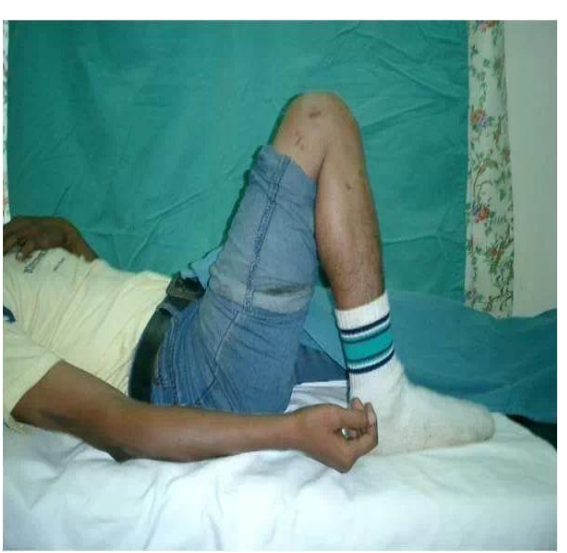

(d)

Fig 3: (a) $x$ rays of a patient with floating knee (b) post operative $x$ ray (c)showing delayed union (d) post operative ROM. 


\section{Results}

93.3\% cases occurred due to motor vehicle accidents and $6.7 \%$ cases were due to self-fall $83.4 \%$ cases were closed type and $16.6 \%$ open type

Table 1: Type of fracture among the subjects

\begin{tabular}{|c|c|c|c|}
\hline & & No. Patients & Percent \\
\hline \multirow{6}{*}{ Type of Fracture } & Closed Muller Type A1 & 23 & 76.7 \\
\hline & Closed Muller Type A2 & 1 & 3.3 \\
\hline & Closed Muller Type A3 & 1 & 3.3 \\
\hline & Open Muller Type A1 & 4 & 13.3 \\
\hline & Open Muller Type A2 & 1 & 3.3 \\
\hline & Total & 30 & 100.0 \\
\hline
\end{tabular}

Majority of the subjects i.e. 76.7\% had Closed Muller type A1 \#, 13.3\% had Open Muller type A1 and 3.3\% had Closed Muller Type A2, Closed Muller Type A3 and Open Muller Type A2 respectively.

Table 2: Post op complications among the subjects

\begin{tabular}{|c|c|c|c|}
\hline & & No. Patients $(\mathbf{n}=30)$ & Percentage \\
\hline Death & & 1 & $3.3 \%$ \\
\hline Screw breakage & & 1 & $3.3 \%$ \\
\hline PE & & 2 & $6.6 \%$ \\
\hline \multirow{2}{*}{ Shortening } & $1 \mathrm{~cm}$ & 2 & $6.6 \%$ \\
\cline { 2 - 4 } & $2 \mathrm{~cm}$ & 1 & $3.3 \%$ \\
\hline Stiffness & & 3 & $10 \%$ \\
\hline Delayed union & & 7 & 23.3 \\
\hline
\end{tabular}

In the study one subject died, one subject had implant failure and $6.6 \%$ had pulmonaryn embolism. 3 subjects had shortening of limbs, 3 subjects had stiffness and 7 subjects had delayed union postoperatively and 1 case showed screw breakage. Average flexion in this study was 115 degree with more than $90 \%$ patients having knee range of motion more than 110 degree. At 3 month follow up $46.7 \%$ cases were united, 53.3\% were still uniting and $46.7 \%$ At 6 month of follow up $73.3 \%$ showed complete union, $23.3 \%$ showed

delayed union. Long term final results were rated using Neer's rating system, which allots points for pain, function, working ability, joint movements, gross and radiological appearance. Neer's score was assigned for each patients after 24 to 36 weeks. Using this scale there were 15(51.7\%) excellent results, $6(20.6 \%)$ good results, $7(24 . \%)$ fair results and $1(3.4 \%)$ poor result.

\section{Discussion}

Table 3

\begin{tabular}{|c|c|c|c|c|}
\hline Series & Age Group (Years) & Average Age & Male (No.) & Female (No.) \\
\hline Seifert J et al. ${ }^{[21]}$ & $17-92$ & 44 & $2917-75 \mathrm{yrs}$ (avg 34.3yrs) & $1819-92 \mathrm{yrs}(\mathrm{avg} 53.8 \mathrm{yrs})$ \\
\hline Gellman RE et al. ${ }^{[20]}$ & $24-84$ & 50 & $1029-61 \mathrm{yrs}$ (avg 39yrs) & 12 26-84yrs(avg 60yrs) \\
\hline Lucas SM et al. ${ }^{[19]}$ & $15-69$ & 39 & 13 & 11 \\
\hline \multirow{2}{*}{ Present } & $18-75$ & $41.27 \pm 17.43 \mathrm{yrs}$. & $21-72$ (avg 38.21 yrs) & $\begin{array}{c}2 \\
45-75(\mathrm{avg} 60 \mathrm{yrs})\end{array}$ \\
\hline
\end{tabular}

Table 4

\begin{tabular}{|c|c|c|c|c|}
\hline Series & Operative time & Follow up & Union rate & Remarks \\
\hline Seifert et al. & --- & $\begin{array}{c}12-37 \text { months } \\
\text { Avg:33weeks }\end{array}$ & $\begin{array}{c}9-17 \text { weeks } \\
\text { Avg :12.6weeks }\end{array}$ & All fractures healed; 1 open reduction done \\
\hline SKV Gupta et al. ${ }^{[22]}$ & & & average time of 7.4 months & 5 cases (9\%) developed nonunion \\
\hline Present & \multirow{2}{*}{ Avg: $83.92 \mathrm{~min}$} & 6months & $\begin{array}{c}24 \text { weeks } \\
73 \%\end{array}$ & $\begin{array}{c}7 \text { delayed union } \\
22 \text { healed }\end{array}$ \\
\hline
\end{tabular}

We used Neer's score since it emphasizes on important patient outcome variables such as pain, functions as related to daily living activities, range of motion, return to work, gross anatomic alignment and radiological evaluation of union and mechanical alignment. However no rating scale is validated to be superior to other. Range of motion was on par with previously reported studies; Kolmert et al. 92 degree, Gile et al. 120degree, Shelton et al. 115 degree, Seinscheimer 100degree, Iannacone 90degree, Gynning 130degree, Henry 105degree, Gellman 104degree and Lucas et al. 100degree. In this study average ROM is 115 degree for all fractures. Younger patients attained better results than the elderly patients. Presumably this is because the younger group adhere to strict and vigorous physiotherapy postoperatively than elderly group. Extensor lag was noted in patients post operatively 5-30 degrees which reduced after physiotherapy and was absent after 1 month of follow up. Most of the patients had their healing excellent alignment without shortening. The $1-2 \mathrm{~cm}$ shortening that occurred in 3 patients but did not affect their function. All of them did well with shoe raise. 1 patient reported with screw breakage due to noncompliance of post-operative protocol and was not willing for a repeat surgery. 2 patients had post-operative fat embolism from which one patient died and the other fully recovered. 3 patients reported with knee stiffness. 7 pts. Showed signs of delayed union at the end of 6 months follow 
up. Dynamisation was done in 2 patients and bone marrow injection was given in 1 patient. Union rates in our set up were prolonged as compared to foreign studies but was comparable to other Indian studies. Further evaluation in this matter is required.

\section{Conclusion}

Retrograde intramedullary supracondylar nail is a good fixation system for distal third femoral fractures, particularly extra-articular type. The operative-time is lessened with decrease in blood loss. If closed reduction can be achieved by not disturbing fracture hematoma and soft tissue. Distal screw related local symptoms is a common problem and is related to implant and technique; and has a definite learning curve. There is no non-union, reduced rates of angular or rotational malunion and delayed unions. Early surgery, closed reduction, at least two screws in each fragment and early postoperative knee mobilization are essential for good union and good knee range of motion. Thus, supracondylar nail is the optimal tool for many supracondylar fractures of femur. It provides rigid fixation in a region of femur, where a widening canal, thin cortices and frequently poor bone stock make fixation difficult. Surgical exposure for nail placement requires significantly less periosteal stripping and soft tissue exposure than that of lateral fixation devices.

\section{References}

1. Whittle AP. Fractures and dislocations. In: Canale ST, Beaty JH, editors. Campbell's operative orthopedics. 11th ed. Philadelphia: Mosby Elsevier, 2008; 3170-3187.

2. O'Brien PJ, Meek RN, Blachut PA, Broekhuyse HM. Fractures distal femur: Rockwood and Greens fractures in adults, 7th ed, Lippincott Williams and wilkins, 2007, 2.

3. Khare A, Mehra M. Retrograde femoral interlocking nail in complex fractures. J Orthop Surg. 2002; 10(1):17-21.

4. Saw A, Lau CP. Supracondylar nailing for difficult distal femur fractures. J Orthop Surg. 2003; 11(20):141-147.

5. Cass J, Sems A. Operative versus non operative management of distal femur fracture in myelopathic non ambulatory patients. Orthopaedics. 2008; 31(11):1-4.

6. Crist B, Rocca GD, Murtha YM. Treatment of acute distal femur fractures. Orthopaedics. J Orthop Trauma. 2008; 31(7):1-10.

7. Sidhu AS, Mann HS, Gurusukhman S, Bassi A, Banga A. Management of distal fracture femur-supracondylar nailing versus open dynamic condylar screw. PbJO, 2011; VII(1):22-26.

8. Muckley T, Wahnert D, Hoffmeier K, Oldenburg GV, Frober R, Hofmann G. Internal fixation of type c- distal femoral fractures in osteoporotic bone.J Bone Joint Surg am. 2011; 16:40-53.

9. Arneson TJ, Melton LJ, Lewallen DG et al. Epidemiology of diaphyseal and distal femoral fractures in Rochester, Minnesota, 1965-1984. Clin Orthop Relat Res. 1988; 234:188-194.

10. Giles JB, Delee JC, Heckman JD, Keever JE. Supracondylar-intercondylar fractures of the femur treated with a supracondylar plate and lag screw. J Bone Joint Surg Am. 1982; 64:864-870.

11. Kuenher Henry W, Stewart MJ, Sisk TD, Wallace SL. Fractures of distal third of femur-A compression method of treatment. J Bone Joint Surg Am. 1966; 48(A):784807.

12. Marcus J, Stewart MJ, Sisk TD, Sidney L. Fractures of distal third of femur - a compression method of treatment. J Bone Joint Surg Am. 1966; 48(4):784-807.

13. Watson-Jones R. Fractures and joint injuries. 6th ed. Church hill Livingstone, 1982, 1003-1070.

14. Charnley J. The closed treatment of common fractures 3rd ed, 1961, 197-204.

15. Enneking WF, Horowitz M. The intraarticular effects of immobilization on the human knee. J Bone Joint Surg. 1972; 54(5):973-975.

16. Schatzker J, Lambert DC. Supracondylar fractures of the femur. Clin Orthop Relat Res. 1979; 136:77-83.

17. Bostman OM. Refracture after removal of a condylar plate from the distal third of the femur. J Bone Joint Surg Am. 1990; 72:1013-1018.

18. Davidson BL. Refracture following plate removal in supracondylarintracondylar femur fractures. Orthopedics. 2003; 26(2):157-159.

19. Helfet DL. Retrograde intramedullary nail of supracondylar fractures of femur. Clin.Orthop Relat Res. 1998; 350:80-84.

20. Lucas SE, Seligson D, Henry SL. Intramedullary supracondylar nailing of femoral fractures: a preliminary report of the GSH supracondylar nail. Clin Orthop Relat Res. 1993; 296:200-206.

21. Gellman RE, Paiement GD, Hellary D. Green Treatment of supracondylar femoral fractures with a retrograde intramedullary nail. CORR. 1996; 332:90-97.

22. Seifert J, Stengal D, Matthes G, Hinz P, Ekkernkamp A, Ostermann PA et al. Retrograde fixation of distal femoral fractures: Results Using a New Nail System. J Orthop Trauma. 2003; 17(7):488-495.

23. Gupta SKV, Govindappa CVS, Yalamanchili RK. Outcome of retrograde intramedullary nailing and locking compression plating of distal femoral fractures in adults. OA Orthopedics. 2013; 1(3):23. 